Brit. J. industr. Med., 1959, 16, 128.

\title{
THE CHEMOTHERAPY OF POISONING BY ORGANOPHOSPHATE ANTICHOLINESTERASES
}

\author{
BY
}

\author{
D. R. DAVIES and A. L. GREEN \\ From the Chemical Defence Experimental Establishment, Porton, Wilts.
}

(RECEIVED FOR PUBLICATION OCTOBER 10, 1958)

\begin{abstract}
Oximes (with or without atropine as an adjunct) have recently been used successfully in the treatment of humans poisoned by organophosphate anticholinesterases. The discovery of the nature of the biochemical lesion in organophosphate poisoning has permitted the design of drugs to repair specifically this particular lesion. This paper reviews historically the researches which led to the development of pyridine-2-aldoxime methiodide (PAM) and its corresponding methanesulphonate (P2S), the two most successful oximes yet tried, and summarizes the theoretical background to their rational use.

Organophosphates are lethal because they inactivate cholinesterase due to phosphorylation of the enzyme's active centre. Consequently two rational lines of treatment are: (a) To find some compound which could be phosphorylated as rapidly as the enzyme and which, if introduced into the body, would protect the enzyme from inhibition by competing with it for the organophosphate, or $(b)$ to find a compound which would restore the activity of the inhibited enzyme by dephosphorylating it. In both cases essentially the same type of compound is needed, namely, one with a high intrinsic reactivity with organophosphoryl compounds, in (a) with the inhibitor itself or in (b) with the phosphorylated enzyme. Types of compounds with either or both of these properties are $o$-dihydroxybenzene derivatives, metal chelates, hydroxylamine, hydroxamic acids, and oximes. Pyridine-2-aldoxime methiodide and methanesulphonate have been by far the most successful as reactivators and in the treatment of poisoned animals.

A brief account is given of the range of compounds for which PAM has been shown to be a successful antidote in intact animals and of the ability of PAM to overcome the signs and symptoms of poisoning both in animals and in man.

Possible lines of future investigations are indicated.
\end{abstract}

Organophosphates with the general structure (I) are among the most toxic of all simple chemical compounds.<smiles>[R2][P+]([R2])([Y])[O-]</smiles>

(I)
$R_{1}$ and $R_{2}$ are alkyl, alkoxy, or alkylamino groups and $X$ is an acid radical such as fluoride, p-nitrophenoxy, or dialkylphosphate.

The signs and symptoms of poisoning include muscarinic, nicotinic, and central nervous system effects, all of which can be attributed to the accumulation of endogenously produced acetylcholine (Koelle and Gilman, 1949). Muscarinic effects include nausea, pallor, sweating, salivation, abdominal cramps, vomiting, involuntary defaecation and urination, miosis, excessive bronchial secretion, and bronchoconstriction. Nicotinic effects include muscular fasciculations and weakness, and in severe poisoning muscular paralysis. Effects in the central nervous system include giddiness, headache, unconsciousness, and finally paralysis of the respiratory centre (Grob, 1956). Death in animals is almost invariably due to respiratory failure resulting from paralysis of the respiratory muscles or respiratory centre, from bronchoconstriction, or from a combination of these effects (de Candole, Douglas, Evans, Holmes, Spencer, Torrance, and Wilson, 1953).

Organophosphates are widely used as insecticides, have some use in medicine in the treatment of myasthenia and glaucoma, and have been considered as potential chemical warfare agents. Fortunately, 
these compounds have not been used in war, but their incautious use in agriculture and their deliberate use as suicidal agents have confronted the physician with an urgent need for satisfactory antidotes.

The early recognition of the similar clinical picture in poisoning by organophosphates and by eserine soon led to the realization that these newer compounds were, like eserine, highly potent anticholinesterases (Adrian, Feldberg, and Kilby, 1947), and that poisoning could be countered by antagonists to the action of acetylcholine, notably atropine. For many years atropine has remained the sole practical antidote to organophosphate poisoning, supported by artificial respiration when needed (Grob, 1956). Unfortunately atropine has many deficiencies. It has highly undesirable physiological effects in its own right and furthermore it will only counteract the muscarinic and some of the central effects of acetylcholine and not the nicotinic effects. Attempts to incorporate acetylcholine antagonists active at neuromuscular junctions in therapeutic mixtures with atropine have sometimes been successful in animals (Parkes and Sacra, 1954) but have not led to any recommended treatment in humans.

In the last three years a group of new drugs, of which the best known is PAM (pyridine-2-aldoxime methiodide or 2-hydroxyiminomethyl-N-methyl pyridinium iodide) (II), has been introduced, which will reverse neuromuscular block due to organo-<smiles></smiles>

phosphates and, in less serious cases of poisoning, may obviate the need for atropine as well. These drugs are not acetylcholine antagonists but work on a completely different principle. Since they are likely to be used in future cases of accidental poisoning it has been thought worth while to give a brief account of their history, of how they act, and of their potentialities in medicine.

Rationale and Development of Newer Antidotes

When the anticholinesterase action of organophosphates was studied kinetically in vitro, it was found that inhibition was progressive with time and, in contrast to inhibition with eserine, was effectively irreversible by dilution or dialysis (Mackworth and Webb, 1948). Further experiments showed that during inhibition the organophosphate combined directly and rapidly with some part of the active centre of the enzyme, resulting in the enzyme being

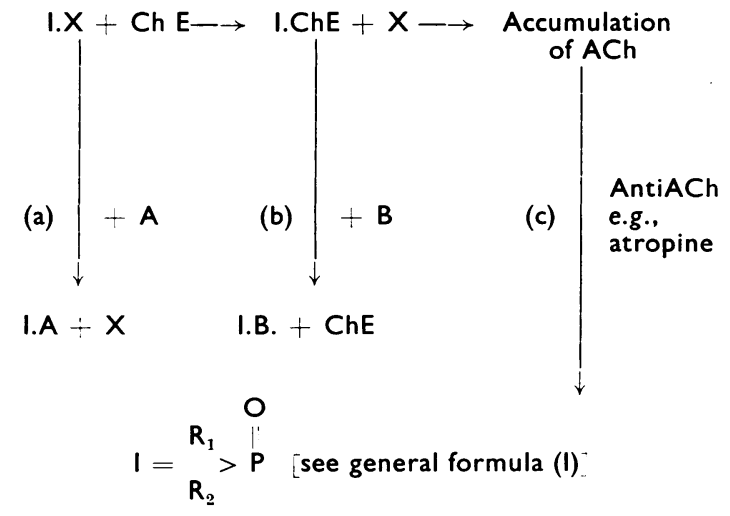

FIG. 1-Diagrammatic scheme of poisoning by organophosphate anticholinesterases.

phosphorylated (Wilson, 1954; Aldridge, 1954). This suggested the possibility of more fundamental methods of treating, organophosphate poisoning. The mechanism of inhibition and the various ways of treatment are illustrated in Fig. 1. The first possible method $(a)$, essentially prophylactic, ${ }^{*}$ is to find some compound (A) which could be phosphorylated as rapidly as the enzyme and which, if introduced into the body, would protect the enzyme from inhibition by competing with it for the organophosphate. The second method $(b)$ is to find some compound (B) which would restore the activity of the inhibited enzyme by dephosphorylating it. In both cases essentially the same type of compound is needed, namely, one with a high intrinsic reactivity with organophosphoryl compounds, in $(a)$ with the inhibitor itself, or in $(b)$ with the phosphorylated enzyme. Accordingly the search for such compounds has generally proceeded along much the same lines.

As a starting point the fact that organophosphates reacted very rapidly with enzymic proteins suggested that their reactivity with simple amino-acids should be examined. Of the normal amino-acids in proteins only tyrosine (Ashbolt and Rydon, 1952) and histidine (Wagner-Jauregg and Hackley, 1953) showed any reactivity at all and even this was not great, but one of the rarer amino-acids, dihydroxyphenylalanine (DOPA) (III), did com-<smiles>NC(Cc1ccc(O)c(O)c1)C(=O)O</smiles>

(III)

bine surprisingly quickly with some of the more reactive organophosphates such as sarin, DFP, and

*In this article prophylaxis is defined as treatment before poisoning and therapy as treatment after poisoning. 
tabun* (Jandorf, Wagner-Jauregg, O'Neill, and Stolberg, 1952; Augustinsson, 1952; Berry, Fellowes, Fraser, Rutland, and Todrick, 1955). This reactivity was in fact independent of the amino-acid portion of the molecule and was entirely due to the $o$-dihydroxyphenyl side-chain. A number of $o$-dihydroxybenzene derivatives were subsequently tested, but the reactivities of all of them fell in a fairly narrow range and for any individual compound the reactivity could be predicted reasonably well from the ionization constant (Epstein, Rosenblatt, and Demek, 1956). No evidence has been given that any of these compounds reactivate inhibited cholinesterase or possess any antidotal activity.

Another approach to compounds capable of decomposing organophosphates is based upon the catalytic effect of heavy metal ions on hydrolytic reactions. Metal ions, particularly when kept from precipitation in neutral solution by aminecomplexing agents, for example, by $2: 2^{\prime}$-dipyridyl (IV), proved to be very effective catalysts for the

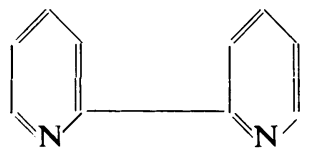

(IV)

hydrolysis of organophosphates (Wagner-Jauregg, Hackley, Lies, Owens, and Proper, 1955; Courtney, Gustafson, Westerback, Hyytiainen, Chaberek, and Martell, 1957), while ammonium molybdate is a potent reactivator of inhibited cholinesterase (Hobbiger, 1956) but none of these metal derivatives have yet been shown to have any value in treatment.

The third source of reactants with organophosphates has proved easily the most profitable. .Hydroxylamine (V) reacts almost instantaneously with carboxylic esters, and in the hope that the same

$$
\mathrm{NH}_{2} \mathrm{OH} \text { (V) }
$$

thing would happen with phosphate esters, the reaction of hydroxylamine with sarin was studied (Jandorf, 1956). $\dagger$ The sarin was decomposed, but relatively slowly. In an attempt to improve on this reactivity many substituted hydroxylamines were examined, eventually leading to the discovery of the high reactivity with organophosphates of hydroxamic acids (Hackley, Plapinger, Stolberg, and Wagner-Jauregg, 1955) and oximes (Green and Saville, 1956). Before the publication of this work hydroxylamine had been tested independently as a possible reactivator of inhibited cholinesterase

\footnotetext{
*The formulae of all the organophosphates referred to will be found in Table 1 .

$\dagger$ This work was originally published as a classified report in 1951.
}

(Wilson, 1952). Some success was achieved with this reagent and also with choline (VI). Choline's reactivating properties were attributed to its ability

$$
\left(\mathrm{CH}_{3}\right)_{3} \mathrm{~N}+\mathrm{CH}_{2} \mathrm{CH}_{2} \mathrm{OH}
$$

to attach itself to the inhibited enzyme by electrostatic attraction between its quaternary ammonium group and the so-called "anionic site" on the inhibited enzyme. The "anionic site" is the name given to that part of cholinesterase to which the choline part of acetylcholine becomes anchored during normal hydrolysis. To try to combine in one compound the active chemical groups of hydroxylamine and choline, namely the hydroxyamino group and the quaternary ammonium group, nicotinhydroxamic acid methiodide (VII) was synthesized (Wilson and Meislich, 1953). This

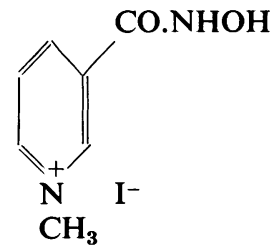

compound proved a better reactivator than either hydroxylamine or choline, although it was shown that other hydroxamic acids were better still, particularly picolinhydroxamic acid (VIII) which does not possess a quaternary ammonium group (Wilson and Ginsburg, 1955a; Jandorf, Crowell,

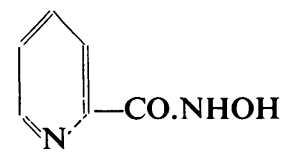

(VIII)

and Levin, 1955). Even so, the activity was still of a comparatively low order. A number of hydroxamic acids have been tested as antidotes to poisoning by sarin (Askew, 1956; Epstein and Freeman, 1956) and by DFP (Funke, Benoit, and Jacob, 1955) but they were only effective in doses far too high to be of practical significance. Studies of the effect of structure on the direct reactivity of hydroxamic acids with organophosphates showed that the deciding factor was, as with the dihydroxybenzenes, the ionization constant and that the reactivity could be predicted reasonably accurately from the ionization constant alone (Stolberg and Mosher, 1957; Green, Sainsbury, Saville, and Stansfield, 1958). It was also possible to show that for reactivity at physiological $p \mathrm{H}(\mathbf{7 . 4 )}$, there was an optimum ionization constant equivalent to a $p \mathrm{~K}_{\mathrm{a}}$ of about 8 (Steinberg, Swidler, and Seltzer, 1957). To test this principle in reactivation many hydroxylamine derivatives were synthesized with $p \mathrm{~K}_{\mathrm{a}} \mathrm{s}$ ranging 
from 5 to 12 (Childs, Davies, Green, and Rutland, 1955). Most of them did reactivate in vitro and the best compounds at $p \mathrm{H} 7.4$ have a $p \mathrm{~K}_{\mathrm{a}}$ around 8 , but this factor alone was not decisive. With some exceptions, oximes with this $p \mathrm{~K}$ tended to be more active than analogous hydroxamic acids. In particular, the oxime PAM (II) was far more active than any other compound tested (Davies and Green, 1955). Meanwhile following the idea that quaternary ammonium groups were important in reactivation, PAM had been synthesized independently and its effectiveness in vitro confirmed (Wilson and Ginsburg, 1955b). This effectiveness is almost certainly due to the presence in PAM of a nucleophilic oxime group and a quaternized nitrogen atom situated at such a distance from the oxime group that it can interact strongly with the "anionic site" on the inhibited enzyme (Green and Smith, 1958).

\section{Treatment of Poisoned Animals with Oximes}

Many oximes have been tested as antidotes to organophosphates with considerable success. In conjunction with atropine PAM was effective against almost all the more common organophosphate anticholinesterases, although when given alone its activity was generally small. In sarinpoisoned rats 1:2-dione monoximes were far more active than PAM when given without atropine (Askew, 1956; Dultz, Epstein, Freeman, Gray, and Weil, 1957). Since there was a possibility that with these compounds atropine could be dispensed with altogether, they .were explored in some detail, but the early promise was not maintained. In species other than rats and against organophosphates other than sarin, their effectiveness was much less and was in general not enhanced by atropine to anything like the same extent as was the effectiveness of PAM (Askew, 1957). A further disadvantage was that the more generally applicable of these compounds, namely 2-oxo-aldoximes such as isonitrosoacetone (MINA) (IX) were moderately toxic being converted in vivo to cyanide (Askew, Davies, Green, and Holmes, 1956). The high therapeutic activity of

$$
\mathrm{CH}_{3} \text {.CO.CH:NOH (IX) }
$$

1:2-dione-monoketoximes, such as diacetylmonoxime (DAM) (X), in sarin-poisoned rats

$$
\mathrm{CH}_{3} \cdot \mathrm{CO} . \mathrm{C}\left(\mathrm{CH}_{3}\right): \mathrm{NOH} \quad(\mathrm{X})
$$

remains an anomaly, as their in vitro reactivating powers are relatively low, while their intrinsic reactivity with sarin is considerably less than that of hydroxamic acids (Askew, Davies, and Green, 1957).

Since the discovery of PAM, its therapeutic value in animals has been widely demonstrated. Table 1 summarizes the results obtained by various authors in the treatment by PAM (or P2S the methanesulphonate salt corresponding to PAM, XI) plus<smiles></smiles>

atropine of poisoning by organophosphate anticholinesterases of most of the types likely to be met in practice. The assessment in the "effect" column is necessarily only crudely quantitative as different authors have generally used different doses of PAM, have adopted different routes of administration, and have given treatment at varied times relative to poisoning. All the compounds which give a form of phosphorylated cholinesterase readily susceptible to reactivation in vitro by PAM have been successfully treated. These compounds are all of structure (I) in which $R_{1}$ and $R_{2}$ are alkyl or alkoxy groups, but not alkylamino groups. Since in the phosphorylated enzyme the group $\mathrm{X}$ is not present, its nature is immaterial. However, phosphorylated cholinesterases (particularly those containing two methoxy or isopropoxy groups) although initially reactivatable become impossible to reactivate after storage both in vitro (Jandorf, Michel, Schaffer, Egan, and Summerson, 1955; Wilson, 1955; Davies and Green, 1956) and in vivo (Hobbiger, 1956; Vandekar and Heath, 1957). With the inhibited enzyme in this form there is at present no known method of reactivation (Aldridge, 1956).

Treatment of parathion poisoning presents a rather different problem from treatment of poisoning by most other organophosphates. Parathion is converted in vivo to paraoxon which is the true lethal agent. As this conversion is slow, repeated dosing with PAM may be necessary before treatment is completely successful (Wilson and Sondheimer, 1957).

In a general sense the antidotal activity of PAM is almost certainly due to its reactivating powers. Animals poisoned with eserine, which does not give a phosphorylated enzyme, or with tabun or OMPA, which give amidophosphoryl enzymes relatively resistant to reactivation, could not be satisfactorily treated with PAM (Kewitz, Wilson, and Nachmansohn, 1956; Bethe, Erdmann, Lendle, and Schmidt, 1957; Wilson and Sondheimer, 1957).

In spite of this, several problems arise when the antidotal action of PAM in intact animals is considered in detail. Most investigations on treatment with PAM have been mainly concerned with survival 
TABLE 1

EFFECT OF PAM (OR P2S) PLUS ATROPINE ON ORGANOPHOSPHATE POISONING IN ANIMALS

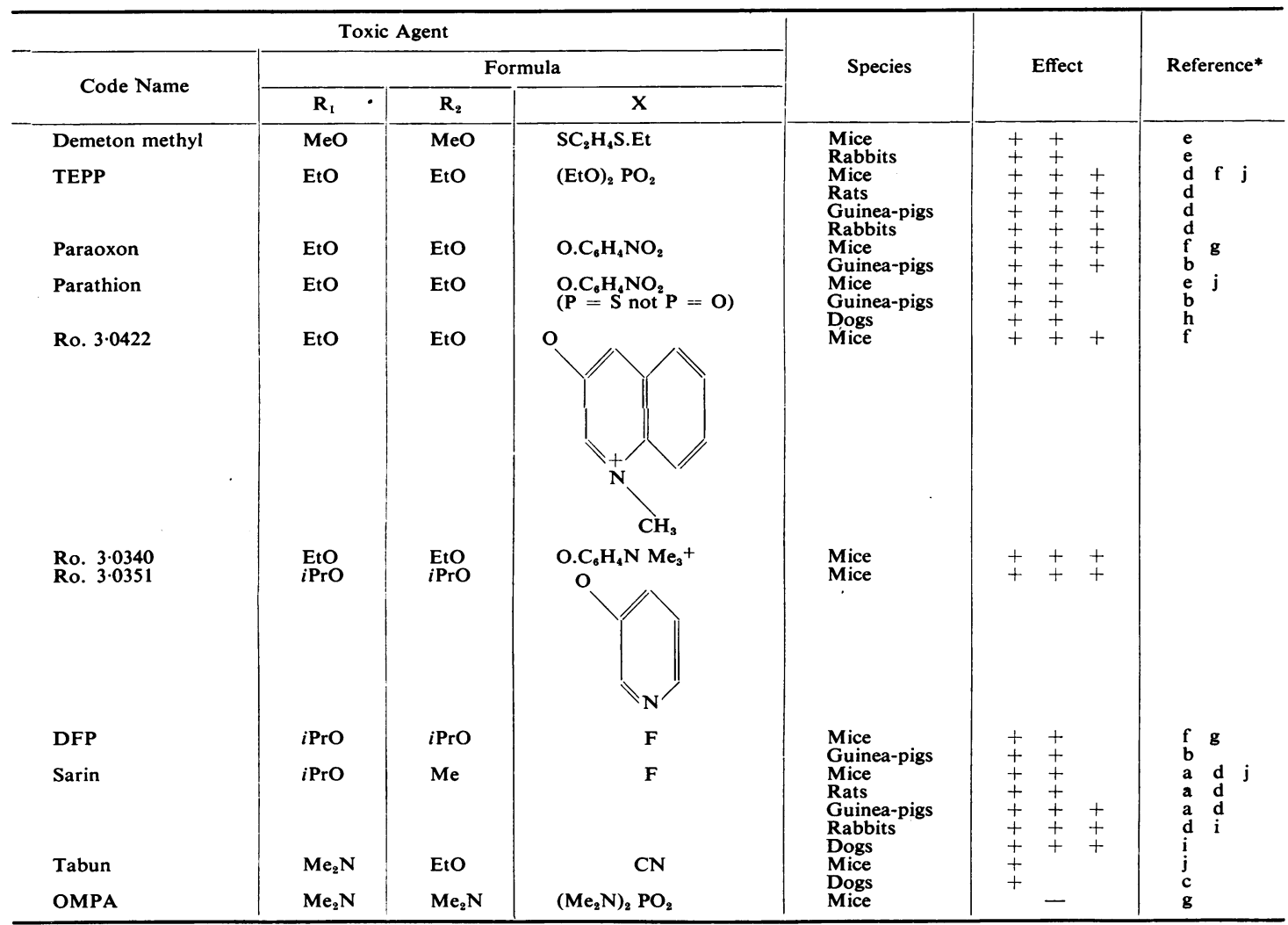

a. Askew (1957)

c. Brown et al. (1957)

c. Brown et al. (1958)

g. Kewitz et al. (1956)

i. Wills et al. (1957)

*REFERENCES

b. Bethe et al. (1957)

d. Davies et al. (1959)

d. Davies et al. (1959)

h. Pepu and Bianchi (1958)

j. Wilson and Sondheimer (1957)

and there is surprisingly little information on how far PAM will counteract the clinical effects of poisoning in animals from non-lethal doses of organophosphate. However, PAM does not generally seem to counteract muscarinic signs, such as salivation and sweating (Hobbiger, 1957), although it will overcome miosis (Kewitz et al., 1956), nor, in the absence of atropine, does it seem to have much effect on central depression of respiration (Brown, Kunkel, Somers, and Wills, 1957). With atropine, it has very marked and beneficial actions upon respiratory failure, which appear to be primarily due to the reversal of neuromuscular block in the respiratory muscles (Brown et al., 1957; Wills, Kunkel, Brown, and Groblewski, 1957). The ability of PAM to overcome neuro- muscular block had previously been shown on isolated tissue preparations (Holmes and Robins, 1955). It will also counteract the bradycardia due to organophosphates and this too may contribute to its therapeutic activity (Bethe et al., 1957). The inability to overcome central respiratory depression may be due to failure of PAM, a quaternary salt, to penetrate into the central nervous system. In intact poisoned animals PAM will rapidly restore blood and muscle cholinesterase but very little effect has been observed on inhibited brain cholinesterase (Hobbiger, 1957; Rutland, 1957; Kewitz, 1957; Kewitz and Nachmansohn, 1957). The relative inability of PAM to enter rat brain has been confirmed by direct estimation of tissue concentrations (Creasey, unpublished results). An attempt to overcome this deficiency was made by 
synthesis of a modification of PAM, termed PAD (XII), which still possessed reactivating properties but which was fat-soluble (Wilson, 1958). Although

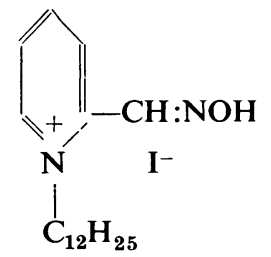

(XII)

this compound did enhance the effect of PAM plus atropine in sarin-poisoned mice, the overall effect was less than that reported by other authors using PAM plus atropine alone (Askew, 1957; Davies, Green, and Willey, 1959) so that the significance of PAD remains uncertain. Its almost complete lack of water solubility makes it of doubtful medicinal value.

\section{Treatment of Organophosphate Poisoning in Man}

The promising results with animals have encouraged the cautious use of PAM in man. In Japan where accidental poisoning with parathion has become a serious problem, PAM has been tried with considerable success (Namba and Hiraki, 1958). Treatment in 39 cases of human poisoning has been described (Namba, 1958), of which 27 exhibited moderate to severe symptoms. In most cases PAM was given without atropine. In all but five of the more severe cases, signs of parathion poisoning almost completely disappeared after the intravenous injection of about $1 \mathrm{~g}$. of PAM. In the other cases further improvement was generally obtained by giving additional PAM. Only one patient died despite being given $2 \mathrm{~g}$. of PAM together with $2 \mathrm{mg}$. of atropine. This patient had taken a very large amount of parathion with the intention of committing suicide. The most striking effects on the course of poisoning were the disappearance of the signs of neuromuscular block, fasciculations and muscle cramps (which cannot be countered by atropine), and also the complete disappearance of disturbances of consciousness. Some of the muscarinic signs such as salivation and excessive bronchial secretion were also dispersed.

The remarkable effect of PAM in clearing consciousness was also noted in a case of suicidal parathion poisoning in Denmark (Karlog, Nimb, and Poulsen, 1958). This effect is difficult to explain if the blood-brain barrier in man is as resistant to the penetration of PAM as it appears to be in animals.

The ability of PAM to counteract the nicotinic signs of anticholinesterase poisoning in man has been confirmed (Grob and Johns, 1958) but no corresponding effect was found on muscarinic or central nervous system signs. The discrepancy between these results and those with parathion described above remains unexplained. There is, however, some evidence that after poisoning with the same anticholinesterase all species do not react equally well to a given reversing agent. It is, therefore, not possible to predict accurately how man would respond to PAM treatment solely on the basis of observations on animals.

Pyridine-2-aldoxime methiodide (and its corresponding methane sulphonate, P2S) is relatively harmless to animals in therapeutically active doses, and it has been suggested from animal experiments that at least $30 \mathrm{mg} . / \mathrm{kg}$. could be given intramuscularly to man with impunity (Davies and Willey, 1958). In normal human subjects P2S has been given without ill-effects in doses of over $5 \mathrm{~g}$. orally or, as a $15 \%$ aqueous solution, in doses of over $1 \mathrm{~g}$. intramuscularly (Ladell, 1958). For intramuscular injection P2S is preferable to PAM because of its vastly increased water solubility. Pyridine-2aldoxime methiodide itself has been administered intravenously to man quite safely in doses of up to 2g. (Namba and Hiraki, 1958; Grob and Johns, 1958).

\section{Possible Future Progress}

Although PAM and P2S have proved successful in both animals and man the development of even better drugs by applying the same principles is still possible. Thus, a new series of compounds has been described recently (Poziomek, Hackley, and Steinberg, 1958) which will reactivate inhibited cholinesterase even more quickly than will PAM and which may be more effective still as therapeutic agents. These compounds are obtained by the coupling of two hydroxyiminomethylpyridine molecules of PAM linked together, e.g., compound TMB4 (XIII). These results have been confirmed (Berry, Davies, and Green, 1959; Hobbiger,

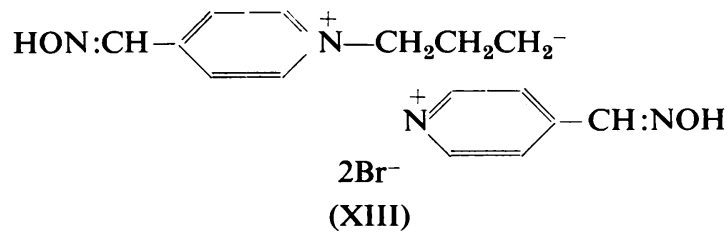

O'Sullivan and Sadler, 1958), but it has been shown that the increased reactivating power is retained by related compounds with only one oxime group and is almost certainly due to the presence of the second charged nitrogen atom.

A source of future antidotes which has not been completely investigated is the metal complexes 
referred to previously. These complexes are still the most effective reagents known for decomposing organophosphate anticholinesterases, yet very few of them appear to have been tested in vivo.

Beside the possible discovery of still better reactants or reactivators, treatment with PAM or P2S may be made more effective by the use of adjuncts other than atropine, given either in addition to atropine or in place of atropine. The fact that no more effective substitute than atropine has been found when given alone does not imply that atropine is necessarily the best adjunct to oximes.

In presenting this review, we have attempted to show how the elucidation of the biochemical lesion in organophosphate poisoning has led fairly quickly to improved therapeutic measures of considerable practical value. While in other cases of poisoning the same methods may be slower in producing a satisfactory form of treatment, nevertheless this procedure does offer a better chance of finding such treatment than the more usual symptomatic approach. Its success against organophosphate poisoning does much to justify the expenditure of considerable effort upon understanding fundamental mechanisms of toxicity.

\section{REFERENCES}

Adrian, E. D., Feldberg, W., and Kilby, B. A. (1947). Brit. J. Pharmacol., 2, 56.

Aldridge, W. N. (1954). Chem. and Ind., p. 473.

(1956). A. R. chem. Soc., 53, 294.

Ashbolt, R. F., and Rydon, H. N. (1952). J. Amer. chem. Soc., 74, 1865.

Askew, B. M. (1956). Brit. J. Pharmacol., 11, 417.

- (1957). Ibid., 12, 340.

- Davies, D. R., and Green, A. L. (1957). Biochem. J., 66, 43P

-_. - _ - and Holmes, R. (1956). Brit. J. Pharmacol., 11, 424

Augustinsson, K. B. (1952). Acta chem. scand., 6, 959.

Berry, W. K., Davies, D. R., and Green, A. L. (1959). Biochem. J., 71, $15 \mathrm{P}$.

—_, Fellowes, K. P., Fraser, P. J., Rutland, J. P., and Todrick, A. (1955). Ibid., 59, 1.

Bethe, K., Erdmann, W. D., Lendle, L., and Schmidt, G. (1957). Naunyn-Schmiledeberg's Arch. exp. Path. Pharmakol., 231, 3.

Brown, R. V., Kunkel, A. M., Somers, L. M., and Willis, J. H. (1957). J. Pharmacol. exp. Ther., 120, 276.

Candole, C. A. de, Douglas, W. W., Evans, C. L., Holmes, R. Spencer, K. E. V., Torrance, R. W., and Wilson, K. M. (1953). Brit. J. Pharmacol., 8, 466.

Childs, A. F., Davies, D. R., Green, A. L., and Rutland, J. P. (1955). Ibid., 10, 462.

Courtney, R. C., Gustafson, R. L., Westerback, S. J., Hyytiainen, H., Chaberek, S. C., and Martell, A. E. (1957). J. Amer. chem. Soc., 79, 3030.

Davies. D. R., and Green, A. L. (1955). Disc. Faraday Soc., 20, 269. - (1956). Biochem. J., 63, 529.
Davis, D. R., and Willey, G. L. (1959). Brit. J. Pharmacol. Vol. 14 (March issue still in press).

-

Dultz, L., Epstein, M. A., Freeman, G., Gray, E. H., and Weil, W. B. (1957). J. Pharmacol. exp. Ther., 119, 522.

Epstein, J., Rosenblatt, D. H., and Demek, M. M. (1956). J. Amer. chem. Soc., 78, 341.

Epstein, M. A., and Freeman, G. (1956). Proc. Soc. exp. Biol. (N.Y.), 92, 660 .

Fournel, J. (1958). C. R. Soc. Biol. (Paris), 1957, 151, 1373.

Funke, A., Benoit, G. and Jacob, J. (1955). C. R. Acad. Sci. (Paris). 240, 2575.

Green, A. L., Sainsbury, G. L., Saville, B., and Stansfield, M. (19.58), J. chem. Soc., p. 1583.

, and Saville, B. (1956). Ibid., p. 3887.

and Smith, H. J. (1958). Biochem. J., 68, 32.

Grob, D. (1956). A.M.A. Arch. intern. Med., 98, 221.

- , and Johns, R. J. (1958). J. Amer. med. Ass., 166, 1855.

Hackley, B. E., Plapinger, R., Stolberg, M., and Wagner-Jauregg, T. (1955). J. Amer. Chem. Soc., 77, 3651.

Hobbiger, F. (1956). Brit. J. Pharmacol., 11, 295.

(1957). Ibid., 12, 438.

, O'Sullivan, D. C., and Sadler, P. W. (1958). Nature, Lond., 182, 1498.

Holmes, R., and Robins, E. L. (1955). Brit. J. Pharmacol., 10, 490.

Jandorf, B. J. (1956). J. Amer. Chem. Soc., 78, 3686.

- Crowell, E. A., and Levin, A. P. (1955). Fed. Proc., 14, 231.

-, Michel, H. O., Schaffer, N. K., Egan, R., and Summerson, W. H. (1955). Disc. Farad. Soc., $20,134$.

—_, Wagner-Jauregg, T., O'Neill, J. J., and Stolberg, M. A. (1952). J. Amer. chem. Soc., 74, 1521.

Karlog, O., Nimb, M., and Poulsen, E. (1958). Ugeskr. Laeg., 120, 177.

Kewitz, H. (1957). Arch. Biochem., 66, 263. , and Nachmansohn, D. (1957). Ibid., 66, 271.

-. Wilson, I. B., and Nachmansohn, D. (1956). Ibid., 64, 456.

Koelle, G. B., and Gilman, A. (1949). Pharmacol. Rev., 1, 166.

Ladell, W. S. S. (1958). Brit. med. J., 2, 141.

Mackworth, J. F., and Webb, E. C. (1948). Biochem. J., 42, 91.

Namba, T. (1958). Naika no Ryoiki (Field of Internal Medicine), 6. 84.

, and Hiraki, K. (1958). J. Amer. med. Ass.; 166, 1834

Parkes, M. W., and Sacra, P. (1954). Brit. J. Pharmacol., 9, 299.

Pepeu, G., and Bianchi, C. (1958). Boll. Soc. ital. Biol. sper., 34, 444.

Poziomek, E. J., Hackley, B. E., and Steinberg, G. M. (1958). J. org. Chem., 23, 714.

Rutland, J. P. (1957). Biochem. J., 66, 43P.

Steinberg, G. M., Swidler, R., and Seltzer, S. (1957). Science, 125, 336.

Stolberg, M. A., and Mosher, W. A. (1957). J. Amer. chem. Soc., 79, 2618 .

Vandekar, M., and Heath, D. F. (1957). Biochem. J., 67, 202.

Wagner-Jauregg, T., and Hackley, B. E. (1953). J. Amer. chem. Soc. 75,2125 . 77,922 . Lies,

Wills, J. H., Kunkel, A. M., Brown, R. V., and Groblewski, G. E. (1957). Science, 125, 743.

Wilson, I. B. (1952). J. biol. Chem., 199, 113.

- (1954). In A Symposium on the Mechanism of Enzyme Action p. 642; ed. W. D. McElroy and B. Glass. John Hopkins Press, Baltimore.

(1955). Disc. Faraday Soc., 20,. 119.

(1958). Biochim. Biophys. Acta., 27, 196

, and Ginsburg, S. (1955a). Arch. Biochem., 54, 569.

(1955b). Biochim. Biophys. Acta, 18, 168.

, and Meislich, E. K. (1953). J. Amer. chem. Soc., 75, 4628.

--, and Sondheimer. F. (1957). Arch. Biochem., 69, 468. 